\title{
The Role of Public Defenders Within the American Justice System
}

\author{
Brianna Fisher $^{\mathrm{a}}$, Patti Thompson ${ }^{\mathrm{a}}$
}

This paper examines the inner workings of the legal system in connection with public defenders and their duties. The factors of total caseload, plea deals, waivers, and bench verdicts were implemented to create a comprehensive means of measuring work ethic, due to their significant presence in the everyday workings of public defenders. Through a meta-analysis of the five most densely populated African American cities within the state of Michigan, the combined and individual weighted mean effect sizes were calculated to determine if there was a strong positive or negative effect of the four factors mentioned above on work ethic. Additionally, both the upper and lower credibility levels were calculated to analyze their proximity to the weighted means. For all four factors tested, the weighted mean effect sizes relate a positive effect of the factors on work ethic, with all means falling closer to their upper credibility levels. These results confirm that the factors of total caseload, plea deals, waivers, and bench verdicts effect how cases are being handled and how clients are being treated.

Key Words: Public defenders, caseload, plea deals, waivers, bench verdicts, Michigan

The significant role of public defenders within the American Justice System has subsided in value as their duties have become increasingly presumed. Public defenders are defined as court appointed lawyers that represent criminals that cannot afford representation themselves and are known for being underpaid and overworked, as well as for having little time to prepare for each case. For example, in Minnesota, state and national standards call for public defenders to carry no more than 400 case units per year, but in 2009, Minnesota public defenders carried an average weighted caseload of 779 case units (Bureau of Justice Statistics). This has, in turn, led to the increased implementation of plea deals, or bargains, which are any agreements in a criminal case between the prosecutor and defendant whereby the defendant agrees to plead guilty to a particular charge in return for some concession from the prosecutor. Plea deals ensure that a conviction will be obtained and help to alleviate the amount of trials carried out by prosecutors. However, these deals are used in place of putting in the time and effort to thoroughly review a case. Because of the large number of convicted criminals in prison due to plea deals, there has been a dramatic increase in mass incarceration and prison overcrowding. Repeatedly, these prisoners are carrying out sentences that are either too long for the crime committed or not long enough, but act as a result of an insufficient plea deal created from the lack of time spent preparing for a case. Additionally, recidivism, or the tendency of a convicted criminal to reoffend, has increased throughout the United States as people are placed in prison on a plea deal and have not served an appropriate sentence. This is clearly an issue that is occurring within the American Justice System, which led to the choice of the research question: What effect does the guarantee of the sixth amendment have on public defenders in highly populated African American cities within the state of Michigan?

\section{Literature Review}

While completing preliminary research, three sources emerged as predominantly important for this paper. In 2011, senior research analyst, holding a doctorate in criminology and criminal justice, Lindsey Devers completed a study for the Bureau of Justice Assistance under the U.S. Department of Justice. Within the study, Devers aimed to prove that plea bargains are a result of disparate treatment concerning both legal and extralegal characteristics. She found that the overwhelming majority (90 to 95 percent) of cases result in plea bargaining, heightening the prosecutorial discretion known to cause discrepancies in sentencing outcomes (Devers 2011). Additionally, Devers found that the majority of research on race and sentencing outcomes shows that African Americans are less likely than whites to receive reduced pleas (Devers 2011). Throughout the exploratory research, this study became the basis for the idea of public defenders and their methods.

This paper will be analyzing the methods and tactics used by public defenders during the pretrial, trial, and post-trial stages. These methods include the use of plea deals, motions (a procedural device to bring a limited, contested issue before a court for decision), and appeals to the jury throughout opening and closing statements. Additionally, this paper will look at statistics from public defenders on the amount of cases they have per year, their funding, and the verdict and method of defense of each case that they represented. In a 2001 research study completed by Dr. Tony Fabelo, director for the Council of State Governments Justice Center and writer at the John F. Kennedy School of Government at Harvard University, he outlined the expectations and values of a successful public defender. A strong public defense system allows for any criminal defendant, no matter their financial status, to obtain a fair chance to win their trial. This promise of impartiality was so important that it was included within the Miranda Rights ("You have the right to an attorney, if you cannot afford an attorney, one will be provided for you by the state"), further ensuring the defendant a public defender. Subsequently, a strong public defense system needs to be built upon a public and political belief of legitimacy. Fabelo found that there are nine elements to an effective public defense system, each building upon the other to determine success. These include independence, coverage, workload, qualifications, support services, training, notification time, access to council, and overall quality representation (Fabelo 2001). Independence, coverage, and workload all affect the individual public defender's work ethic, whether they have the right amount of time and energy to put into each case. Oppositely, qualification and training are dependent upon the public defender themselves, and are specific per person. The use of support services and access 
to council is imperative for public defenders to work efficiently and quickly to maximize the success of their cases. Finally, quality representation is determined by not only the success of the trial but also by the amount of effort put in by the public defender. For a successful public defense system, all nine of these elements must work in harmony and without many problems (Fabelo 2001). However, situations such as increased caseloads and district pressures, as well as the thought of each trial as just another case in comparison to a client, have decreased the productivity of the public defense system.

Upon further investigation, a 2016 study completed by Reshaad Shirazi, UC Berkeley School of Law graduate, creates an imperative urgency to abandon the use of the stereotyped "high crime" areas by judges became significant to the development of the research question. These areas are used to determine if there is a reasonable suspicion for a crime to be committed in that location. Conversely, these areas create a racist jurisprudence within the trial due to their disproportionately high African American population. Shirazi based his research off the fact that poor African Americans are more likely to reside in inner-city neighborhoods than whites due to institutional and political racism. Even in areas where circuit courts have begun to decrease their dependence on high crime areas as procedural factors, the judgement is still present within the people of the court. Shirazi writes "But even when courts address the high crime area claim, it often results in judicial notice confirming the officers' ad-hoc [sic] determination that the suspect was in a high-crime area" (Shirazi 2016). Significantly, Shirazi found that classifying areas as high crime violates the Equal Protection Clause of the Constitution under the fourteenth amendment ("Nor shall any State [...] deny to any person within its jurisdiction the equal protection of the laws"); a provision that, if come into question in regards to a race, would set equality back hundreds of years. Unlike other studies, research has not been completed on public defenders in the state of Michigan, especially in Detroit, which is one the most densely populated African American city in the United States. With this in mind and the intent to uncover racial disparities within the American justice system, the gap of this research on public defenders will focus on the five most densely populated African American cities within the state of Michigan: Highland Park (92.4\%), Benton Harbor (85.3\%), Detroit (82.7\%), Muskegon Heights (77.3\%) and Inkster (71.6\%) (US Census 2010).

Unlike other research that has been completed, this paper will be analyzing how the assurance of the sixth amendment, or the right to council, to criminal defendants affects the work ethic of public defenders. No study focuses on the situation created when a lawyer is guaranteed, and the paper will determine if there is a change in perspective per situation. Additionally, there is currently no study that analyzes public defenders in densely populated African American communities, as well as the effects of racial jurisprudence in trials where the defendant was represented by a public defender. Uniquely, this research will provide a perspective into the American justice system to determine whether public defenders are affected by legal expectations.

\section{Method}

Removing the drama created by courtroom testimonies and statements, court records consist of quantitative data and statistics detailing the raw facts of each trial. These enumerations each relate to a total number of cases, as well as a breakdown of each disposition, or the court's final determination of a case or issue. Because of this, this research was completed by a metaanalysis of the statistics of the court records from Highland Park, Benton Harbor, Detroit, Muskegon Heights, and Inkster. The sole purpose of a meta-analysis is to combine statistics from multiple factors and analyze their relationships by determining whether there were patterns expressed by the data. This method was applied to this data by looking at the five cities, deciding if there were trends among the records that were present in each set of data, such as an increase in plea deals, guilty verdicts, and waiver usage. By completing a meta-analysis of statistical records from public defenders' offices within the five chosen cities, the paper will be able to determine if there is a correlation between the guarantee of the sixth amendment and work ethic. Additionally, by choosing the five most densely populated African American cities in Michigan from the United States Census, bias will be eliminated that would be created from a specific choice of city. When the trends were established, the actual numbers were able to be compared to further examine the statistics.

Regarded as a subdivision under the meta-analysis assessment, the Hunter and Schmidt Method was implemented as the main statistical test for this paper. Used to isolate and correct sources of error within a group of statistics, this method generates the weighted mean effect size. This test reveals whether there is a strong positive or negative effect of work ethic within public defenders, particularly in the case of this study. To calculate the weighted mean effect size, the formula $r=\frac{\sum_{i=1}^{k} n_{i} r_{i}}{\sum_{i=1}^{k} n_{i}}$ can be used, where $r$ is the weighted mean of the set of data and $\mathrm{n}$ is the sample size. Additionally, the credibility intervals can be calculated to determine the range of accuracy of the weighted mean effect size through the formulas Credibility Interval Upper $_{2}=r+1.96 \sqrt{\sigma_{p}^{2}}$ and Credibility Interval ${ }_{\text {Lower }}=r-1.96 \sqrt{\sigma_{p}^{2}}$. The four factors tested were total caseload, plea deals / admissions, waivers, and bench verdicts. Because these factors are a significant component of the job of a public defender, they can be used to represent the sixth amendment.

Meta-analysis was the best choice of a research method because it allowed for a comparison and analysis of statistics through an impartial method. To guarantee that the results were not biased, the court records were all obtained from the same legal database (courts.michigan.gov), provided by the Michigan Indigent Defense Commission. No other research method would have yielded the same results because it would have been harder to clearly establish the patterns between the five cities of the study. The main focus of this research is to determine if there is a crisis in the work ethic of public defenders, which was most effectively established through a meta-analysis of courtroom statistics.

\section{Results and Findings}


To determine the effect of the sixth amendment on public defenders, the statistics used for the meta-analysis needed to be chosen from the court records provided by Michigan. To first understand the tables, one must understand the case type codes seen in Table 1 that are used to differentiate the court records. (Caseload Reports 2016 and 2017. Retrieved from https://courts.michigan.gov/education/stats/caseload/pages/2016-2017-caseload-reports.aspx)

\section{Table 1: Case Type Codes}

\begin{tabular}{|c|c|}
\hline EX & Extradition (Misdemeanor) \\
\hline FY & Felony (Felony) \\
\hline OM & Ordinance Misdemeanor Non-Traffic (Misdemeanor) \\
\hline SM & Statute Misdemeanor Non-Traffic (Misdemeanor) \\
\hline FD & Felony Drunk Driving (Felony) \\
\hline FT & Felony Traffic (Felony) \\
\hline OD & Ordinance Drunk Driving (Misdemeanor) \\
\hline OI & Ordinance Civil Infraction Traffic (Civil Infraction / Parking) \\
\hline OT & Ordinance Misdemeanor Traffic (Misdemeanor) \\
\hline SI & Statute Civil Infraction Traffic (Civil Infraction / Parking) \\
\hline SD & Statute Drunk Driving (Misdemeanor) \\
\hline ST & Statute Misdemeanor Traffic (Misdemeanor) \\
\hline $\mathrm{OK}$ & Ordinance Parking (Civil Infraction / Parking) \\
\hline $\mathrm{ON}$ & Ordinance Civil Infraction Non-Traffic (Civil Infraction / Parking) \\
\hline SK & Statute Parking (Civil Infraction / Parking) \\
\hline SN & Statute Civil Infraction Non-Traffic (Civil Infraction / Parking) \\
\hline
\end{tabular}

For each city, the total caseload, guilty pleas/admissions, waivers (allows the case to proceed to trial without a preliminary hearing), and bench verdict cases (trial by a judge rather than a jury) were analyzed for both 2016 and 2017 and separated into Tables 2 through 9 such that each city was directly correlated to the next. Tables $\mathbf{2}$ through 9 represent the five cities that this research is focused on, as well as the number of cases that ended in the specific outcome indicated in the title (i.e. total caseload, guilty plea).

Table 2: Total Caseload Per City (2016)

\begin{tabular}{|l|l|l|l|l|l|l|l|l|l|l|l|l|l|l|l|l|l|}
\hline City & EX & FY & OM & SM & FD & FT & OD & OI & OT & SD & SI & ST & OK & ON & SK & SN & TOTAL \\
\hline $\begin{array}{l}\text { Highland } \\
\text { Park }\end{array}$ & 0 & 293 & 1772 & 124 & 8 & 44 & 9 & 7521 & 2892 & 4 & 58 & 107 & 863 & 5 & 0 & 0 & 13,700 \\
\hline $\begin{array}{l}\text { Benton } \\
\text { Harbor }\end{array}$ & 97 & 3340 & 718 & 3787 & 144 & 114 & 60 & 4607 & 815 & 676 & 1287 & 6313 & 172 & 206 & 203 & 759 & 34,798 \\
\hline Detroit & 0 & 12931 & 51700 & 6505 & 188 & 389 & 848 & 133058 & 156728 & 731 & 14835 & 14414 & 85330 & 1428 & 148 & 937 & 480,170 \\
\hline $\begin{array}{l}\text { Muskegon } \\
\text { Heights }\end{array}$ & 0 & 2243 & 797 & 5459 & 87 & 53 & 139 & 8980 & 2828 & 583 & 3925 & 2912 & 265 & 636 & 52 & 282 & 29,241 \\
\hline
\end{tabular}


Journal of Student Research ${ }_{(2019)}$

Research Article

\begin{tabular}{|l|l|l|l|l|l|l|l|l|l|l|l|l|l|l|l|l|l|}
\hline Inkster & 0 & 292 & 861 & 132 & 12 & 11 & 17 & 5906 & 1512 & 12 & 198 & 331 & 701 & 0 & 0 & 0 & 9,985 \\
\hline
\end{tabular}

Table 3: Total Guilty Pleas / Admissions (2016)

\begin{tabular}{|l|l|l|l|l|l|l|l|l|l|l|l|l|l|l|l|l|l|}
\hline City & EX & FY & OM & SM & FD & FT & OD & OI & OT & SD & SI & ST & OK & ON & SK & SN & TOTAL \\
\hline $\begin{array}{l}\text { Highland } \\
\text { Park }\end{array}$ & 0 & 16 & 499 & 36 & 2 & 13 & 4 & 1398 & 1229 & 1 & 9 & 51 & 212 & 0 & 0 & 0 & 3,258 \\
\hline $\begin{array}{l}\text { Benton } \\
\text { Harbor }\end{array}$ & 0 & 737 & 434 & 2106 & 67 & 10 & 49 & 2741 & 435 & 567 & 6394 & 3391 & 0 & 0 & 0 & 0 & 16,931 \\
\hline Detroit & 0 & 107 & 6958 & 578 & 6 & 5 & 295 & 22382 & 22213 & 192 & 3028 & 2022 & 0 & 0 & 0 & 0 & 57,786 \\
\hline $\begin{array}{l}\text { Muskegon } \\
\text { Heights }\end{array}$ & 0 & 177 & 365 & 1964 & 0 & 4 & 104 & 4723 & 1267 & 394 & 2094 & 1400 & 0 & 0 & 0 & 0 & 12,492 \\
\hline Inkster & 0 & 11 & 183 & 48 & 1 & 0 & 4 & 3193 & 540 & 7 & 49 & 85 & 0 & 0 & 0 & 0 & 4,121 \\
\hline
\end{tabular}

Table 4: Total Waivers (2016)

\begin{tabular}{|l|l|l|l|l|l|l|l|l|l|l|l|l|l|l|l|l|l|}
\hline City & EX & FY & OM & SM & FD & FT & OD & OI & OT & SD & SI & ST & OK & ON & SK & SN & TOTAL \\
\hline $\begin{array}{l}\text { Highland } \\
\text { Park }\end{array}$ & 0 & 0 & 0 & 0 & 0 & 0 & 0 & 0 & 0 & 0 & 0 & 0 & 210 & 0 & 0 & 0 & 210 \\
\hline $\begin{array}{l}\text { Benton } \\
\text { Harbor }\end{array}$ & 0 & 0 & 0 & 0 & 0 & 0 & 0 & 0 & 0 & 0 & 0 & 0 & 71 & 78 & 84 & 299 & 532 \\
\hline Detroit & 0 & 0 & 0 & 0 & 0 & 0 & 0 & 0 & 0 & 0 & 0 & 0 & 219 & 374 & 44 & 262 & 899 \\
\hline $\begin{array}{l}\text { Muskegon } \\
\text { Heights }\end{array}$ & 0 & 0 & 0 & 0 & 0 & 0 & 0 & 0 & 0 & 0 & 0 & 0 & 53 & 84 & 15 & 189 & 341 \\
\hline Inkster & 0 & 0 & 0 & 0 & 0 & 0 & 0 & 0 & 0 & 0 & 0 & 0 & 188 & 0 & 0 & 0 & 188 \\
\hline
\end{tabular}

Table 5: Total Bench Verdict Cases (2016)

\begin{tabular}{|l|l|l|l|l|l|l|l|l|l|l|l|l|l|l|l|l|l|}
\hline City & EX & FY & OM & SM & FD & FT & OD & OI & OT & SD & SI & ST & OK & ON & SK & SN & TOTAL \\
\hline $\begin{array}{l}\text { Highland } \\
\text { Park }\end{array}$ & 0 & 0 & 6 & 2 & 0 & 0 & 0 & 1126 & 6 & 0 & 9 & 1 & 0 & 0 & 0 & 0 & 1,150 \\
\hline $\begin{array}{l}\text { Benton } \\
\text { Harbor }\end{array}$ & 0 & 0 & 0 & 1 & 0 & 0 & 0 & 33 & 0 & 0 & 90 & 0 & 33 & 103 & 99 & 301 & 124 \\
\hline Detroit & 0 & 2 & 60 & 80 & 0 & 0 & 3 & 7378 & 86 & 1 & 794 & 7 & 0 & 0 & 0 & 0 & 8,411 \\
\hline $\begin{array}{l}\text { Muskegon } \\
\text { Heights }\end{array}$ & 0 & 0 & 10 & 48 & 0 & 1 & 0 & 644 & 2 & 3 & 295 & 11 & 0 & 0 & 0 & 0 & 1,014 \\
\hline Inkster & 0 & 1 & 2 & 2 & 0 & 0 & 0 & 110 & 0 & 0 & 1 & 1 & 0 & 0 & 0 & 0 & 117 \\
\hline
\end{tabular}

Table 6: Total Caseload Per City (2017)

\begin{tabular}{|l|l|l|l|l|l|l|l|l|l|l|l|l|l|l|l|l|l|}
\hline City & EX & FY & OM & SM & FD & FT & OD & OI & OT & SD & SI & ST & OK & ON & SK & SN & TOTAL \\
\hline $\begin{array}{l}\text { Highland } \\
\text { Park }\end{array}$ & 0 & 202 & 1297 & 119 & 0 & 22 & 33 & 7447 & 3148 & 5 & 73 & 112 & 902 & 7 & 0 & 1 & 13,368 \\
\hline $\begin{array}{l}\text { Benton } \\
\text { Harbor }\end{array}$ & 170 & 3346 & 840 & 3457 & 159 & 116 & 46 & 3342 & 768 & 659 & 12338 & 6046 & 101 & 218 & 188 & 587 & 32,381 \\
\hline Detroit & 0 & 12641 & 42780 & 5579 & 172 & 361 & 726 & 117115 & 158558 & 550 & 10030 & 10797 & 53453 & 1363 & 93 & 680 & 414,898 \\
\hline $\begin{array}{l}\text { Muskegon } \\
\text { Heights }\end{array}$ & 0 & 2431 & 785 & 5056 & 95 & 75 & 142 & 8903 & 3070 & 522 & 3534 & 2482 & 68 & 964 & 28 & 264 & 28,419 \\
\hline Inkster & 0 & 324 & 2815 & 124 & 7 & 14 & 32 & 2674 & 1209 & 19 & 127 & 246 & 547 & 0 & 0 & 0 & 8,138 \\
\hline
\end{tabular}


Table 7: Total Guilty Pleas / Admissions (2017)

\begin{tabular}{|l|l|l|l|l|l|l|l|l|l|l|l|l|l|l|l|l|l|}
\hline City & EX & FY & OM & SM & FD & FT & OD & OI & OT & SD & SI & ST & OK & ON & SK & SN & TOTAL \\
\hline $\begin{array}{l}\text { Highland } \\
\text { Park }\end{array}$ & 0 & 11 & 271 & 27 & 0 & 2 & 20 & 871 & 1160 & 1 & 15 & 40 & 0 & 0 & 0 & 0 & 2,418 \\
\hline $\begin{array}{l}\text { Benton } \\
\text { Harbor }\end{array}$ & 0 & 711 & 432 & 1807 & 71 & 16 & 35 & 2164 & 420 & 527 & 7181 & 3056 & 0 & 0 & 0 & 0 & 16,420 \\
\hline Detroit & 0 & 73 & 6576 & 523 & 16 & 1 & 301 & 19433 & 23537 & 140 & 2069 & 1556 & 0 & 0 & 0 & 0 & 54,225 \\
\hline $\begin{array}{l}\text { Muskegon } \\
\text { Heights }\end{array}$ & 0 & 177 & 376 & 1851 & 1 & 4 & 93 & 4832 & 1413 & 350 & 2017 & 1145 & 0 & 0 & 0 & 0 & 12,259 \\
\hline Inkster & 0 & 19 & 566 & 30 & 0 & 1 & 20 & 1343 & 396 & 10 & 31 & 86 & 0 & 0 & 0 & 0 & 2,502 \\
\hline
\end{tabular}

Table 8: Total Waivers (2017)

\begin{tabular}{|l|l|l|l|l|l|l|l|l|l|l|l|l|l|l|l|l|l|}
\hline City & EX & FY & OM & SM & FD & FT & OD & OI & OT & SD & SI & ST & OK & ON & SK & SN & TOTAL \\
\hline $\begin{array}{l}\text { Highland } \\
\text { Park }\end{array}$ & 0 & 0 & 0 & 0 & 0 & 0 & 0 & 0 & 0 & 0 & 0 & 0 & 212 & 0 & 0 & 0 & 212 \\
\hline $\begin{array}{l}\text { Benton } \\
\text { Harbor }\end{array}$ & 0 & 0 & 0 & 0 & 0 & 0 & 0 & 0 & 0 & 0 & 0 & 0 & 33 & 103 & 99 & 301 & 536 \\
\hline Detroit & 0 & 0 & 0 & 0 & 0 & 0 & 0 & 0 & 0 & 0 & 0 & 0 & 213 & 344 & 43 & 147 & 747 \\
\hline $\begin{array}{l}\text { Muskegon } \\
\text { Heights }\end{array}$ & 0 & 0 & 0 & 0 & 0 & 0 & 0 & 0 & 0 & 0 & 0 & 0 & 27 & 95 & 16 & 178 & 316 \\
\hline Inkster & 0 & 0 & 0 & 0 & 0 & 0 & 0 & 0 & 0 & 0 & 0 & 0 & 141 & 0 & 0 & 0 & 141 \\
\hline
\end{tabular}

Table 9: Total Bench Verdict Cases (2017)

\begin{tabular}{|l|l|l|l|l|l|l|l|l|l|l|l|l|l|l|l|l|l|}
\hline City & EX & FY & OM & SM & FD & FT & OD & OI & OT & SD & SI & ST & OK & ON & SK & SN & TOTAL \\
\hline $\begin{array}{l}\text { Highland } \\
\text { Park }\end{array}$ & 0 & 0 & 4 & 7 & 0 & 0 & 0 & 1243 & 11 & 0 & 4 & 2 & 0 & 0 & 0 & 0 & 1,271 \\
\hline $\begin{array}{l}\text { Benton } \\
\text { Harbor }\end{array}$ & 0 & 0 & 1 & 0 & 0 & 0 & 0 & 23 & 0 & 0 & 106 & 0 & 0 & 0 & 0 & 0 & 130 \\
\hline Detroit & 0 & 3 & 69 & 79 & 0 & 0 & 1 & 7655 & 96 & 2 & 477 & 13 & 0 & 0 & 0 & 0 & 8,395 \\
\hline $\begin{array}{l}\text { Muskegon } \\
\text { Heights }\end{array}$ & 0 & 0 & 6 & 56 & 0 & 0 & 0 & 527 & 6 & 2 & 236 & 9 & 0 & 0 & 0 & 0 & 842 \\
\hline Inkster & 0 & 1 & 9 & 1 & 0 & 0 & 0 & 66 & 0 & 0 & 5 & 0 & 0 & 0 & 0 & 0 & 82 \\
\hline
\end{tabular}

The information from Tables 2 through 9 was provided by the State of Michigan.

Caseload Reports. (2016 and 2017). Retrieved from https://courts.michigan.gov/education/stats/caseload/pages/2016-caseloadreports.aspx

To determine the effect of different dispositions on public defender's work ethic, the Hunter and Schmidt model had to be implemented for each disposition to compare the two years (2016 and 2017). The total caseload per city was first looked at. The effect size, s, was calculated by subtracting the mean of the 2017 cases from the mean of the 2016 cases and then dividing the solution by the standard deviation of the 2016 cases, or by this formula:

$$
s=\frac{\text { mean of the } 2016 \text { cases }- \text { mean of the } 2017 \text { cases }}{\text { standard deviation of the } 2016 \text { cases }}
$$

To calculate s for the total caseload, values from Tables 2 and 6 were substituted into the above equation, starting with Highland Park.

\section{Highland Park:}

Mean of the 2016 cases: $\frac{13700}{16}=856.25$ 
Mean of the 2017 cases: $\frac{13368}{16}=835.50$

Standard deviation of the 2016 cases: $\sqrt{\frac{\sum(x-\text { mean of } 2016)^{2}}{N}}$, where $\mathrm{x}$ is the value per different case and $\mathrm{N}$ is the sample size, which is 16 because there are 16 dispositions.

$(x-\text { mean of } 2016)^{2}=$

1. $(0-856.25)^{2}=733164.06$

2. $(293-856.25)^{2}=317250.56$

3. $(1772-856.25)^{2}=915.75$

4. $(124-856.25)^{2}=536190.06$

5. $(8-856.25)^{2}=719528.06$

6. $(44-856.25)^{2}=659750.06$

7. $(9-856.25)^{2}=717832.56$

8. $(7521-856.25)^{2}=44418892.56$

9. $(2892-856.25)^{2}=4144278.06$

10. $(4-856.25)^{2}=726330.06$

11. $(58-856.25)^{2}=637203.06$

12. $(170-856.25)^{2}=561375.56$

13. $(863-856.25)^{2}=45.56$

14. $(5-856.25)^{2}=724626.56$

15. $(0-856.25)^{2}=733164.06$

16. $(0-856.25)^{2}=733164.06$

When all these values are added together, the sum is 5636710.69 . This can be substituted into the standard deviation formula stated above:

$$
\text { Standard deviation }=\sqrt{\frac{5636710.69}{16}}=1876.89
$$

Once the standard deviation has been calculated, it can be put into the equation to find effect size, s, for Highland Park's total caseload.

$$
s=\frac{856.25-835.50}{1876.894}=0.011
$$

This set of procedures can be replicated for the other four cities.

\section{Benton Harbor:}

Mean of the 2016 cases: $\frac{34798}{16}=2174.875$ 
Mean of the 2017 cases: $\frac{32381}{16}=2021.8125$

Standard deviation of the 2016 cases: $\sqrt{\frac{\sum(x-\text { mean of } 2016)^{2}}{N}}$

When calculated, $\sum(x-\text { mean of } 2016)^{2}=64945356.76$. This can be substituted into the standard deviation formula above:

$$
\sqrt{\frac{64945356.76}{16}}=2014.72
$$

Once the standard deviation has been calculated, it can be put into the equation to find effect size, s, for Benton Harbor's total caseload.

$$
s=\frac{2174.875-2023.8125}{2014.72}=0.075
$$

Detroit:

Mean of the 2016 cases: $\frac{480170}{16}=30010.625$

Mean of the 2017 cases: $\frac{414898}{16}=25931.125$

Standard deviation of the 2016 cases: $\sqrt{\frac{\sum(x-\text { mean of } 2016)^{2}}{N}}$

When calculated, $\sum(x-\text { mean of } 2016)^{2}=38,153,740,030$. This can be substituted into the standard deviation formula above:

$$
\sqrt{\frac{38,153,740,030}{16}}=48832.46
$$

Once the standard deviation has been calculated, it can be put into the equation to find effect size, s, for Detroit's total caseload.

$$
s=\frac{30010.625-25931.125}{48832.46}=0.084
$$

\section{Muskegon Heights:}

Mean of the 2016 cases: $\frac{29241}{16}=1827.56$

Mean of the 2017 cases: $\frac{28419}{16}=1776.19$

Standard deviation of the 2016 cases: $\sqrt{\frac{\sum(x-\text { mean of } 2016)^{2}}{N}}$

When calculated, $\sum(x-\text { mean of } 2016)^{2}=95477073.94$. This can be substituted into the standard deviation formula above:

$$
\sqrt{\frac{95477073.94}{16}}=2442.81
$$


Once the standard deviation has been calculated, it can be put into the equation to find effect size, s, for Muskegon Heights' total caseload.

$$
s=\frac{1827.56-1776.19}{2442.81}=0.021
$$

Inkster:

Mean of the 2016 cases: $\frac{9985}{16}=624.06$

Mean of the 2017 cases: $\frac{8138}{16}=508.63$

Standard deviation of the 2016 cases: $\sqrt{\frac{\sum(x-\text { mean of } 2016)^{2}}{N}}$

When calculated, $\sum(x-\text { mean of } 2016)^{2}=32420588.93$. This can be substituted into the standard deviation formula above:

$$
\sqrt{\frac{32420588.93}{16}}=1423.48
$$

Once the standard deviation has been calculated, it can be put into the equation to find effect size, s, for Inkster's total caseload.

$$
s=\frac{624.06-508.63}{1423.48}=0.08
$$

Now, since both s and $\mathrm{N}$ are known for all five cities, they can be tabulated to find the weighted mean effect size in relation to total caseload, which is computed in Table 10.

Table 10: Effect and Sample Size in Relation to Total Caseload

\begin{tabular}{|c|c|c|c|}
\hline City & N & S & Ns \\
\hline Highland Park & 16 & 0.011 & 0.18 \\
\hline Benton Harbor & 16 & 0.075 & 1.20 \\
\hline Detroit & 16 & 0.084 & 0.34 \\
\hline Muskegon Heights & 16 & 0.021 & 1.30 \\
\hline Inkster & 16 & & 0.081 \\
\hline
\end{tabular}


Finally, to calculate the mean weighted effect size, the formula $r=\frac{\sum_{i=1}^{k} n_{i} r_{i}}{\sum_{i=1}^{k} n_{i}}$ needs to be implimented. To do so, the total sample size is multiplied by the effect size (Ns) and is divided by the sample size (N):

$$
r_{1}=\frac{4.36}{80}=0.0545
$$

Since $r_{1}$ has been calculated, $\boldsymbol{r}_{2}$ through $\boldsymbol{r}_{4}$ were computed in relation to total guilty pleas / admissions, total waivers, and total bench verdict cases.

To calculate s for the guilty pleas / admissions, values from Tables 3 and 7 were substituted into the above equation, starting with Highland Park.

\section{Highland Park:}

Mean of the 2016 cases: $\frac{3258}{16}=203.625$

Mean of the 2017 cases: $\frac{2418}{16}=151.125$

Standard deviation of the 2016 cases: $\sqrt{\frac{\sum(x-\text { mean of } 2016)^{2}}{N}}$

When calculated, $\sum(x-\text { mean of } 2016)^{2}=3013466.751$. This can be substituted into the standard deviation formula above:

$$
\sqrt{\frac{3013466.751}{16}}=433.98
$$

Once the standard deviation has been calculated, it can be put into the equation to find effect size, s, for Highland Park's total plea deals / admissions.

$$
s=\frac{203.625-151.125}{433.98}=0.121
$$

\section{Benton Harbor:}

Mean of the 2016 cases: $\frac{3258}{16}=203.625$

Mean of the 2017 cases: $\frac{2418}{16}=151.125$

Standard deviation of the 2016 cases: $\sqrt{\frac{\sum(x-\text { mean of } 2016)^{2}}{N}}$

When calculated, $\sum(x-\text { mean of } 2016)^{2}=47663490.4$. This can be substituted into the standard deviation formula above:

$$
\sqrt{\frac{47663490.4}{16}}=1725.97
$$

Once the standard deviation has been calculated, it can be put into the equation to find effect size, s, for Benton Harbor's total plea deals / admissions.

$$
s=\frac{1058.19-1026.25}{1725.97}=0.019
$$


Detroit:

Mean of the 2016 cases: $\frac{57786}{16}=3611.625$

Mean of the 2017 cases: $\frac{54225}{16}=3389.0625$

Standard deviation of the 2016 cases: $\sqrt{\frac{\sum(x-\text { mean of } 2016)^{2}}{N}}$

When calculated, $\sum(x-\text { mean of } 2016)^{2}=847810445.7$. This can be substituted into the standard deviation formula above:

$$
\sqrt{\frac{847810445.7}{16}}=7279.30
$$

Once the standard deviation has been calculated, it can be put into the equation to find effect size, s, for Detroit's total plea deals / admissions.

$$
s=\frac{3611.625-3389.0625}{7279.30}=0.031
$$

\section{Muskegon Heights:}

Mean of the 2016 cases: $\frac{12492}{16}=780.75$

Mean of the 2017 cases: $\frac{12259}{16}=766.1875$

Standard deviation of the 2016 cases: $\sqrt{\frac{\sum(x-\text { mean of } 2016)^{2}}{N}}$

When calculated, $\sum(x-\text { mean of 2016 })^{2}=24691643$. This can be substituted into the standard deviation formula above:

$$
\sqrt{\frac{24691643}{16}}=1242.28
$$

Once the standard deviation has been calculated, it can be put into the equation to find effect size, s, for Muskegon Heights' total plea deals / admissions.

$$
s=\frac{780.75-766.1875}{1242.28}=0.012
$$

Inkster:

Mean of the 2016 cases: $\frac{4121}{16}=257.56$

Mean of the 2017 cases: $\frac{156.38}{16}=156.38$

Standard deviation of the 2016 cases: $\sqrt{\frac{\sum(x-\text { mean of } 2016)^{2}}{N}}$

When calculated, $\sum(x-\text { mean of } 2016)^{2}=9232239.938$. This can be substituted into the standard deviation formula above: 


$$
\sqrt{\frac{9232239.938}{16}}=759.62
$$

Once the standard deviation has been calculated, it can be put into the equation to find effect size, s, for Inkster's total plea deals / admissions.

$$
s=\frac{257.56-156.38}{759.62}=0.133
$$

Now, since both s and $\mathrm{N}$ are known for all five cities, they can be tabulated to find the weighted mean effect size in relation to total plea deals / admissions, which is computed in Table 11.

Table 11: Effect and Sample Size in Relation to Total Plea Deals / Admissions

\begin{tabular}{|c|c|c|c|}
\hline City & N & S & Ns \\
\hline Highland Park & 16 & 0.121 & 0.30 \\
\hline Benton Harbor & 16 & 0.019 & 0.49 \\
\hline Detroit & 16 & 0.031 & 0.19 \\
\hline Muskegon Heights & 16 & 0.012 & 2.13 \\
\hline Inkster & 16 & 0.133 & $\mathbf{5 . 0 5}$ \\
\hline
\end{tabular}

Finally, to calculate the mean weighted effect size in relation to plea deals / admissions, the formula $r=\frac{\sum_{i=1}^{k} n_{i} r_{i}}{\sum_{i=1}^{k} n_{i}}$ needs to

be implimented. To do so, the total sample size is multiplied by the effect size (Ns) and is divided by the sample size (N):

$$
r_{2}=\frac{5.05}{80}=0.0631
$$

To calculate s for the total waivers, values from Tables 4 and 8 were substituted into the above equation, starting with Highland Park.

\section{Highland Park:}

Mean of the 2016 cases: $\frac{210}{16}=13.125$

Mean of the 2017 cases: $\frac{212}{16}=13.25$

Standard deviation of the 2016 cases: $\sqrt{\frac{\sum(x-\text { mean of } 2016)^{2}}{N}}$

When calculated, $\sum(x-\text { mean of } 2016)^{2}=41343.75$. This can be substituted into the standard deviation formula above: 


$$
\sqrt{\frac{41343.75}{16}}=50.83
$$

Once the standard deviation has been calculated, it can be put into the equation to find effect size, s, for Highland Park's total waivers.

$$
s=\frac{13.125-13.255}{50.83}=-0.002
$$

Benton Heights:

Mean of the 2016 cases: $\frac{532}{16}=33.25$

Mean of the 2017 cases: $\frac{536}{16}=33.50$

Standard deviation of the 2016 cases: $\sqrt{\frac{\sum(x-\text { mean of } 2016)^{2}}{N}}$

When calculated, $\sum(x-\text { mean of 2016 })^{2}=90093.25$. This can be substituted into the standard deviation formula above:

$$
\sqrt{\frac{90093.25}{16}}=50.83
$$

Once the standard deviation has been calculated, it can be put into the equation to find effect size, s, for Benton Heights' total waivers.

$$
s=\frac{33.25-33.50}{50.83}=-0.005
$$

\section{Detroit:}

Mean of the 2016 cases: $\frac{899}{16}=56.1875$

Mean of the 2017 cases: $\frac{747}{16}=46.6875$

Standard deviation of the 2016 cases: $\sqrt{\frac{\sum(x-\text { mean of } 2016)^{2}}{N}}$

When calculated, $\sum(x-\text { mean of } 2016)^{2}=207904.4376$. This can be substituted into the standard deviation formula above:

$$
\sqrt{\frac{207904.4376}{16}}=113.99
$$

Once the standard deviation has been calculated, it can be put into the equation to find effect size, s, for Detroit's total waivers.

$$
s=\frac{56.1875-46.6875}{113.99}=0.083
$$

\section{Muskegon Heights:}

Mean of the 2016 cases: $\frac{341}{16}=21.3125$

Mean of the 2017 cases: $\frac{316}{16}=19.75$ 
Standard deviation of the 2016 cases: $\sqrt{\frac{\sum(x-\text { mean of } 2016)^{2}}{N}}$

When calculated, $\sum(x-\text { mean of } 2016)^{2}=38543.4375$. This can be substituted into the standard deviation formula above:

$$
\sqrt{\frac{38543.4375}{16}}=49.081
$$

Once the standard deviation has been calculated, it can be put into the equation to find effect size, s, for Muskegon Heights' total waivers.

$$
s=\frac{21.3125-19.75}{49.081}=0.032
$$

Inkster:

Mean of the 2016 cases: $\frac{188}{16}=11.75$

Mean of the 2017 cases: $\frac{141}{16}=8.8125$

Standard deviation of the 2016 cases: $\sqrt{\frac{\sum(x-\text { mean of } 2016)^{2}}{N}}$

When calculated, $\sum(x-\text { mean of } 2016)^{2}=33135$. This can be substituted into the standard deviation formula above:

$$
\sqrt{\frac{33135}{16}}=45.508
$$

Once the standard deviation has been calculated, it can be put into the equation to find effect size, s, for Inkster's total waivers.

$$
s=\frac{11.75-8.8125}{45.508}=0.065
$$

Now, since both s and $\mathrm{N}$ are known for all five cities, they can be tabulated to find the weighted mean effect size in relation to total waivers, which is computed in Table 12.

Table 12: Effect and Sample Size in Relation to Total Waivers

\begin{tabular}{|c|c|c|c|}
\hline City & N & S & Ns \\
\hline Highland Park & 16 & -0.002 & -0.04 \\
\hline Benton Harbor & 16 & -0.005 & -0.08 \\
\hline Detroit & 16 & 0.083 & 1.33 \\
\hline Muskegon Heights & 16 & 0.032 & 0.51 \\
\hline
\end{tabular}




\begin{tabular}{|c|c|c|c|}
\hline Total & $\mathbf{8 0}$ & $\mathbf{0 . 1 7 3}$ & 2.75 \\
\hline
\end{tabular}

Finally, to calculate the mean weighted effect size in relation to waivers, the formula $r=\frac{\sum_{i=1}^{k} n_{i} r_{i}}{\sum_{i=1}^{k} n_{i}}$ needs to be implimented.

To do so, the total sample size is multiplied by the effect size (Ns) and is divided by the sample size (N):

$$
r_{3}=\frac{2.75}{80}=0.0341
$$

To calculate s for the total bench verdict cases, values from Tables 5 and 9 were substituted into the above equation, starting with Highland Park.

\section{Highland Park:}

Mean of the 2016 cases: $\frac{1150}{16}=71.875$

Mean of the 2017 cases: $\frac{1271}{16}=79.4375$

Standard deviation of the 2016 cases: $\sqrt{\frac{\sum(x-\text { mean of } 2016)^{2}}{N}}$

When calculated, $\sum(x-\text { mean of } 2016)^{2}=1181038.235$. This can be substituted into the standard deviation formula above:

$$
\sqrt{\frac{1181038.235_{-}}{16}}=271.69
$$

Once the standard deviation has been calculated, it can be put into the equation to find effect size, s, for Highland Park's total waivers.

$$
s=\frac{71.875-79.4375}{271.69}=-0.028
$$

\section{Benton Harbor:}

Mean of the 2016 cases: $\frac{124}{16}=7.75$

Mean of the 2017 cases: $\frac{130}{16}=8.125$

Standard deviation of the 2016 cases: $\sqrt{\frac{\sum(x-\text { mean of } 2016)^{2}}{N}}$

When calculated, $\sum(x-\text { mean of } 2016)^{2}=112021.0001$. This can be substituted into the standard deviation formula above:

$$
\sqrt{\frac{112021.0001}{16}}=83.674
$$

Once the standard deviation has been calculated, it can be put into the equation to find effect size, s, for Benton Harbor's total waivers.

$$
s=\frac{7.75-8.125}{83.674}=-0.004
$$


Detroit:

Mean of the 2016 cases: $\frac{8411}{16}=525.6875$

Mean of the 2017 cases: $\frac{8395}{16}=524.6875$

Standard deviation of the 2016 cases: $\sqrt{\frac{\sum(x-\text { mean of } 2016)^{2}}{N}}$

When calculated, $\Sigma(x-\text { mean of } 2016)^{2}=3900359.499$. This can be substituted into the standard deviation formula above:

$$
\sqrt{\frac{3900359.499}{16}}=493.733
$$

Once the standard deviation has been calculated, it can be put into the equation to find effect size, s, for Detroit's total waivers.

$$
s=\frac{525.6875-524.6875}{493.733}=0.002
$$

\section{Muskegon Heights:}

Mean of the 2016 cases: $\frac{1014}{16}=63.375$

Mean of the 2017 cases: $\frac{842}{16}=52.625$

Standard deviation of the 2016 cases: $\sqrt{\frac{\sum(x-\text { mean of } 2016)^{2}}{N}}$

When calculated, $\sum(x-\text { mean of } 2016)^{2}=439031.7462$. This can be substituted into the standard deviation formula above:

$$
\sqrt{\frac{439031.7462}{16}}=165.649
$$

Once the standard deviation has been calculated, it can be put into the equation to find effect size, s, for Muskegon Height's total waivers.

$$
\begin{gathered}
s=\frac{63.375-52.625}{165.649}=0.061 \\
\text { Inkster: }
\end{gathered}
$$

Mean of the 2016 cases: $\frac{117}{16}=7.3125$

Mean of the 2017 cases: $\frac{82}{16}=5.125$

Standard deviation of the 2016 cases: $\sqrt{\frac{\sum(x-\text { mean of } 2016)^{2}}{N}}$

When calculated, $\sum(x-\text { mean of } 2016)^{2}=11255.44094$. This can be substituted into the standard deviation formula above:

$$
\sqrt{\frac{11255.44094}{16}}=26.523
$$


Once the standard deviation has been calculated, it can be put into the equation to find effect size, s, for Inkster's total waivers.

$$
s=\frac{7.3125-5.125}{26.523}=0.082
$$

Now, since both s and $\mathrm{N}$ are known for all five cities, they can be tabulated to find the weighted mean effect size in relation to total waivers, which is computed in Table 13.

Table 13: Effect and Sample Size in Relation to Total Bench Verdict Cases

\begin{tabular}{|c|c|c|c|}
\hline City & N & S & Ns \\
\hline Highland Park & 16 & -0.028 & -0.45 \\
\hline Benton Harbor & 16 & -0.004 & 0.03 \\
\hline Detroit & 16 & 0.002 & 1.38 \\
\hline Muskegon Heights & 16 & 0.061 & 1.32 \\
\hline Inkster & 16 & & $\mathbf{1 0 . 5 6}$ \\
\hline
\end{tabular}

Finally, to calculate the mean weighted effect size in relation to the total bench verdict cases, the formula $r=\frac{\sum_{i=1}^{k} n_{i} r_{i}}{\sum_{i=1}^{k} n_{i}}$ needs to be implimented. To do so, the total sample size is multiplied by the effect size (Ns) and is divided by the sample size $(\mathrm{N})$ :

$$
r_{4}=\frac{1.56}{80}=0.0195
$$

Since all four weighted mean effect sizes have been calculated, they can be embedded into Table 14 so that each mean can be compared for each factor.

Table 14: Weighted Mean Effect Sizes for $r_{1}$ through $\boldsymbol{r}_{4}$

\begin{tabular}{|c|c|}
\hline Factor & $\boldsymbol{r}$ \\
\hline Caseload & 0.0545 \\
\hline Guilty Pleas / Admissions & 0.0631 \\
\hline Waivers & 0.0341 \\
\hline Bench Verdict & 0.0195 \\
\hline Total & $\mathbf{0 . 1 7 1 2}$ \\
\hline
\end{tabular}


To determine the accuracy of the weighted mean effect sizes, the credibility interval from the Hunter and Schmidt method was implemented. To do so, the values for $r_{1}$ through $r_{4}$ were put into Table 15 through Table 18 so that the values could be calculated.

Table 15: Calculating Credibility Intervals for Total Caseload

\begin{tabular}{|c|c|c|c|c|c|}
\hline City & $\mathbf{N}$ & $\mathbf{S}$ & $(\boldsymbol{s}-(\mathbf{0 . 0 5 4 5}))^{\mathbf{2}}$ & $\mathbf{N}\left(\boldsymbol{s}-(\mathbf{0 . 0 5 4 5})^{\mathbf{2}}\right)$ & 0.030 \\
\hline Highland Park & 16 & 0.011 & 0.002 & 0.18 \\
\hline Benton Harbor & 16 & 0.075 & 0.0004 & 0.007 \\
\hline Detroit & 16 & 0.084 & 0.0012 & 0.014 \\
\hline Muskegon Heights & 16 & 0.021 & 0.0007 & 0.34 \\
\hline Inkster & 16 & 0.081 & & 0.112 \\
\hline Total & $\mathbf{8 0}$ & & & $\mathbf{0 . 1 7 5}$ \\
\hline
\end{tabular}

The Upper and Lower Credibility Interval can be calculated by these formulas:

$$
\begin{aligned}
& \text { Credibility Interval }_{\text {Upper }}=r+1.96 \sqrt{\sigma_{p}^{2}} \\
& \text { Credibility Interval }{ }_{\text {Lower }}=r-1.96 \sqrt{\sigma_{p}^{2}}
\end{aligned}
$$

To find $\sigma_{p}^{2}, \sigma_{e}^{2}$ needs to be subrtracted from $\sigma_{r}^{2}$.

To caluculate $\sigma_{e}^{2}$, The sum of $N(s-(0.0545))$ can be divided by the sum of N.

$$
\sigma_{e}^{2}=\frac{0.175}{80}=0.0022
$$

Now, $\sigma_{r}^{2}$ can be calculated by the formula $\sigma_{r}^{2}=\frac{\left(1-s^{-2}\right)^{2}}{N_{1}-1}$, where $N_{1}$ is the average sample size.

$$
=\frac{\left(1-(0.0545)^{2}\right)^{2}}{\frac{80}{5}-1}=0.0663
$$

Since $\sigma_{r}^{2}$ and $\sigma_{e}^{2}$ have been found, they can be subtracted to find $\sigma_{p}^{2}$.

$$
\begin{gathered}
\sigma_{p}^{2}=\sigma_{r}^{2}-\sigma_{e}^{2} \\
=0.0663-0.0022=0.0641
\end{gathered}
$$

This value is then used to create the $95 \%$ credibility interval:

$$
\begin{aligned}
& \text { Credibility Interval }_{\text {Upper }}=0.0545+1.96 \sqrt{0.0641}=0.55 \\
& \text { Credibility Interval }_{\text {Lower }}=0.0545-1.96 \sqrt{0.064}=-0.44
\end{aligned}
$$

Because 0.0545 falls closer to 0.55 , there is a strong effect of total caseload on work ethic.

This same method can be repeated for total guilty pleas / admissions, waivers, and bench verdicts. 
Journal of Student Research ${ }_{(2019)}$

Research Article

Table 16: Calculating Credibility Intervals for Total Plea Deals / Admissions

\begin{tabular}{|c|c|c|c|c|c|}
\hline City & $\mathbf{N}$ & $\mathbf{S}$ & $(\boldsymbol{s}-(\mathbf{0 . 0 6 3 1}))^{\mathbf{2}}$ & $\boldsymbol{N}\left(\boldsymbol{s}-(\mathbf{0 . 0 6 3 1})^{\mathbf{2}}\right)$ & 0.054 \\
\hline Highland Park & 16 & 0.121 & 0.0034 & 0.030 \\
\hline Benton Harbor & 16 & 0.019 & 0.0019 & 0.30 \\
\hline Detroit & 16 & 0.031 & 0.0010 & 0.042 \\
\hline Muskegon Heights & 16 & 0.012 & 0.0049 & 0.19 \\
\hline Inkster & 16 & 0.133 & & 0.078 \\
\hline Total & $\mathbf{8 0}$ & & & $\mathbf{0 . 7 0}$ \\
\hline
\end{tabular}

$$
\begin{gathered}
\sigma_{p}^{2}=\sigma_{r}^{2}-\sigma_{e}^{2} \\
=0.066-0.00875=0.057
\end{gathered}
$$

This value is then used to create the $95 \%$ credibility interval:

$$
\begin{aligned}
& \text { Credibility Interval }_{\text {Upper }}=0.0631+1.96 \sqrt{0.057}=0.53 \\
& \text { Credibility Interval } \mathrm{L}_{\text {Lower }}=0.0631-1.96 \sqrt{0.057}=-0.40
\end{aligned}
$$

Because 0.0631 falls closer to 0.53 , there is a strong effect of total plea deals / admissions on work ethic.

Table 17: Calculating Credibility Intervals for Total Waivers

\begin{tabular}{|c|c|c|c|c|}
\hline City & $\mathbf{N}$ & $\mathbf{S}$ & $(\boldsymbol{s}-(\mathbf{0 . 0 3 4 1}))^{\mathbf{2}}$ & $\mathbf{N}\left(\boldsymbol{s}-(\mathbf{0 . 0 3 4 1})^{\mathbf{2}}\right)$ \\
\hline Highland Park & 16 & -0.002 & 0.0013 & 0.021 \\
\hline Benton Harbor & 16 & -0.005 & 0.0015 & 0.024 \\
\hline Detroit & 16 & 0.083 & 0.0024 & 0.038 \\
\hline Muskegon Heights & 16 & 0.032 & 0.000004 & 0.000006 \\
\hline Inkster & 16 & 0.065 & 0.0016 & 1.33 \\
\hline Total & $\mathbf{8 0}$ & & & $\mathbf{0 . 0 9 9}$ \\
\hline
\end{tabular}

$$
\begin{gathered}
\sigma_{p}^{2}=\sigma_{r}^{2}-\sigma_{e}^{2} \\
=0.0665-0.001=0.066
\end{gathered}
$$

This value is then used to create the $95 \%$ credibility interval:

$$
\begin{aligned}
& \text { Credibility Interval }_{\text {Upper }}=0.0341+1.96 \sqrt{0.066}=0.54 \\
& \text { Credibility Interval }_{\text {Lower }}=0.0341-1.96 \sqrt{0.066}=-0.47
\end{aligned}
$$


Because 0.0341 falls closer to 0.53 , there is a strong effect of total waivers on work ethic.

Table 18: Calculating Credibility Intervals for Total Bench Verdict Cases

\begin{tabular}{|c|c|c|c|c|c|}
\hline City & $\mathbf{N}$ & $\mathbf{S}$ & $(\boldsymbol{s}-(\mathbf{0 . 0 1 9 5}))^{\mathbf{2}}$ & $\boldsymbol{N}\left(\boldsymbol{s}-(\mathbf{0 . 0 1 9 5})^{\mathbf{2}}\right)$ & Ns \\
\hline Highland Park & 16 & -0.028 & 0.0023 & 0.037 & -0.45 \\
\hline Benton Harbor & 16 & -0.004 & 0.0006 & 0.0096 & -0.72 \\
\hline Detroit & 16 & 0.002 & 0.0024 & 0.038 & 0.03 \\
\hline Muskegon Heights & 16 & 0.061 & 0.0017 & 0.027 & 1.38 \\
\hline Inkster & 16 & 0.082 & 0.0039 & 0.062 & 1.32 \\
\hline Total & $\mathbf{8 0}$ & & & $\mathbf{0 . 1 7 4}$ & $\mathbf{1 . 5 6}$ \\
\hline
\end{tabular}

$$
\begin{gathered}
\sigma_{p}^{2}=\sigma_{r}^{2}-\sigma_{e}^{2} \\
=0.0666-0.00022=0.066
\end{gathered}
$$

This value is then used to create the $95 \%$ credibility interval:

$$
\begin{aligned}
& \text { Credibility Interval }_{\text {Upper }}=0.0195+1.96 \sqrt{0.066}=0.52 \\
& \text { Credibility Interval }_{\text {Lower }}=0.0195-1.96 \sqrt{0.066}=-0.48
\end{aligned}
$$

Because 0.0195 falls closer to 0.53 , there is a strong effect of total bench verdict cases on work ethic.

\section{Analysis and Discussion}

For all four factors tested, the combined and individual weighted mean effect sizes in the state of Michigan demonstrate a positive effect that the chosen factors influence public defender work ethic. Because the combined weighted mean effect size for all four factors was 0.1712 , which is positive, it relates a strong correlation between the influence of caseload, plea deals / admissions, waivers, and bench verdicts on labor principles. Correspondingly, the weighted mean effect sizes for each factor fell closer to the upper credibility interval than the lower. This confirms that these factors have an impression on public defenders, which is ultimately a result of the guarantee of the sixth amendment.

Total caseload was first thought of as the major deterrent to public defender work ethic. Logically, if an attorney for either side has too many cases to work on at once, no significant work could get done. As seen in Table 10, all s' (effect sizes) for the five cities were positive, with three out of five of the Ns' (sample size times effect size) greater than 1 . When these values were substituted to find $r_{1}$, the value was 0.0545 . Because this value is positive, it can be concluded that the factor of total caseload does have a strong effect on work ethic. By testing the credibility intervals of the weighted mean effect sizes in Table 15, this research was able confirm the decrease in work effort. The upper credibility interval was 0.55 , while the lower credibility interval was 0.44. Because the weighted mean effect size of 0.0545 falls closer to 0.55 , it can be deduced that there is a strong effect of total caseload on work ethic in the state of Michigan.

Similarly, the total number of plea deals / admissions was first thought of when completing this research. As seen in Table 11, the weighted mean effect size for plea deals / admissions was 0.0631. Additionally, cities such as Highland Park and Inkster had Ns' that were plus or minus .10 of 2. Such a high number indicates the significant effect of plea deals / admissions. Even higher than total caseloads, the mean reflects a positive value that influences work ethic. To further determine the reliability of this research, the upper and lower credibility intervals were calculated in Table 16. The upper credibility interval was 0.53 , while the lower interval was -0.40 . Because 0.0631 falls closer to 0.53 , this research can conclude that there is a strong effect of plea deals / admissions on work ethic in the state of Michigan.

Equally important, the total number of waivers, a motion that allows a trial to proceed without a preliminary hearing, was chosen. By neglecting the preliminary hearing, the amount of time a public defender spends on a case decreases. When first analyzing the court records provided by the state of Michigan, an initial trend of " 0 " was seen for all cases except Ordinance Parking (Civil Infraction / Parking), Ordinance Civil Infraction Non-Traffic (Civil Infraction / Parking), Statute Parking (Civil Infraction / Parking), and Statute Civil Infraction Non-Traffic (Civil Infraction / Parking). Additionally, the s' for Highland Park and Benton Harbor were negative. This information foreshadowed a negative weighted mean effect size, which, however, was incorrect. As shown in Table 12, the weighted mean effect size for total waivers was 0.0341 . Disproving the initial thoughts of this 
paper, the number of total waivers does influence work ethic as distinguished with the positive weighted mean effect size. As a waiver is implemented, public defenders have other time to work on other cases. While this sounds like a convenience to the attorney, the omitting of the preliminary hearing leaves both defendants and judges alike without prior knowledge on the trial other than the police report. This can leave all parties uninformed and unprepared for the trial. Additionally, Table 17 displays the credibility interval for the total waivers. The upper credibility interval was 0.54 , while the lower was -0.47 . Despite having a lower weighted effect mean size than both the total caseload and plea deals / admissions, the total waivers had a larger range for the 95 percentiles of accuracy of the test results. Because 0.0321 fell closer to 0.53 , it can be concluded that there is a strong effect of total waivers on work ethic in the state of Michigan.

Finally, total bench verdict cases, or trial by a judge, were tested. When first evaluated, this factor was deemed not as important as guilty pleas or the total caseload, because the data was less than the previous factors. This was further seen when the s' for Highland Park and Benton Harbor were negative. However, when the other three cities were looked at and the weighted mean effect size was calculated, the suspicions were proven incorrect. In actuality, the weighted mean effect size was 0.0195 . While less significant than the other four cities, the value was still positive and effects work ethic. To further qualify this, the credibility interval was determined. The upper interval was 0.52 , while the lower interval was -0.48 . Because 0.0195 fell closer to 0.52 , it can be ultimately presumed that a bench verdict effects work ethic in the state of Michigan, just like total caseload, plea deals / admissions, and waivers.

\section{Conclusion}

Summary

These findings, for all four of the factors, signify the effect that the sixth amendment has on public defender work ethic in the state of Michigan. Each calculated weighted mean relates the fact that public defender work ethic is decreasing. Since each tested factor plays a role in the amount of time and effort that a public defender spends on a case, they can be directly correlated to produce a means of measuring commitment and attention to each client. When a person of a lower income or social class is arrested, they are assigned to a public defender who will work their case, officially decided by the U.S. Supreme Court in Gideon v. Wainwright (Gideon was denied a lawyer for his trial, and he represented himself and lost. He appealed, and the Court held that the Sixth Amendment's guarantee of counsel is a fundamental right essential to a fair trial and, as such, applies the states through the Due Process Clause of the Fourteenth Amendment). According to Robert P. Mosteller, professor at the University of North Carolina School of Law, over $80 \%$ of people who are charged with felonies are indigent, or lacking food, clothing, and other necessities due to poverty. Due to this demand for lawyers, $73 \%$ of the country's public defender offices exceed the maximum recommended limit of cases (U.S. Department of Justice). This excessive amount of cases leaves public defenders with little time to prepare for each case and little knowledge of each defendant. In return, more public defenders lower their standards of work because they simply do not have the time to handle multiple cases. As tested for, total caseload does directly contribute to this decrease in attention to each client, which is such a significant problem within the American justice system. Anyone put on trial deserves, and is required by law, to have an attentive and interested lawyer to defend them. When lawyers take on too many cases, they ultimately contribute to the decline in effectiveness of the legal system. If a legal system cannot act effectively, there is no way to guarantee that justice will guide the decisions of prosecutors and defenders alike.

In the same vein as total caseload, the implementation of a plea deal allows an attorney to cut out the time spent going to trial and arguing in court. While viewed as an advantage to public defenders with time restraints, plea deals are usually seen as shortcuts during a case. 97\% of federal cases end in a plea deal, with 94\% for state cases (Bureau of Justice Statistics). Although helpful to overworked public defenders, plea deals often leave people in jail either serving excessive sentences or "getting off easy," receiving a lesser sentence just because they did not go to trial. This result is extremely significant because people are legally required to be put in jail for an accurate sentence in relation to the crime committed. When they are not, their sentence helps to weaken, and possibly destroy, the justice system. Additionally, recidivism is a significant problem within America that is caused by plea deals. According to the National Institute of Justice, about two-thirds (67.8\%) of released prisoners were rearrested within three years of their release and about three-quarters (76.6\%) were rearrested by the end of five years after their release. When criminals spend only a short amount of time in jail because they were given a reduced sentence by plea deal, they are more likely to think that they will get lucky again next time if they commit a crime and get caught. The usage of plea deals leads to a continuous cycle and constantly increasing rate of recidivism, which plagues cities all over the nation. By implementing plea deals in cases only when it is necessary, criminals will be sentenced to more accurate punishments in relation to the degree of their crime.

Correspondingly, the use of waivers has negative effects on public defenders. A preliminary hearing is incredibly significant to the outcome of the trial, as this is the first chance of prosecutors, public defenders, and judges to hear of the case. According to practicing criminal defense attorney Mike Worgul, "As a defendant, you only stand to gain from a preliminary hearing, as you cannot be sentenced based solely on what is said by the prosecution in these hearings." The hearing gives all parties the opportunity to discuss charges, present evidence, and call and cross-examine witness. By waiving the right to the hearing, a defender loses all the chances to determine whether the prosecutor has evidence beyond a reasonable doubt and, in the best case, drop the charges altogether. While waiving a preliminary hearing can give public defenders more time to work on the case, the significance of what would have taken place outweighs any benefits.

Furthermore, a bench verdict has a considerable effect on how public defenders act and view each case. Since the verdict of the case is not determined by a jury, the public defender cannot apply the same methods during the pretrial, trial, and posttrial stages. According to HG.org, a website that specializes in legal resources and proceedings, "Juries also tend to be much easier audiences than judges. Communicating with a jury is more about telling a compelling story." Instead of handpicking a jury during voir dire, a preliminary examination of a witness or a juror by a judge or council, that relates to the defendant, a judge that has been 
trained to look at a case strictly for facts presides over the trial. This, in conjunction with lowering the chances of a not guilty verdict, reduces the time an attorney spends focused on courtroom tactics, and ultimately the time spent on the case. Additionally, voir dire is such a significant process during the preparation for the trial that almost accurately predicts the verdict of the case regarding the members of the jury. When an African American teenager is on trial, it is in the best interest of the defendant to pick members of a jury that are either African American or parents, because they can relate and empathize with the defendant. This is the essential foundation of the art of voir dire, which is a carefully crafted social science used to predict the best outcomes of a trial. As stated by Board Certified Specialist in Federal and State Criminal Law James Davis, "Voir dire plays a critical function in assuring the criminal defendant that his [constitutional] right to an impartial jury will be honored." When there is a bench verdict, the public defender cannot challenge, or even remove, the judge like they could with a juror; therefore, they are obliged to that judge no matter their beliefs.

Implications

To combat these significant problems within the American justice system, two solutions can be implemented for overall success. First, and the most obvious, public defender offices, specifically in Michigan, need to have an increase of funding so that they can complete their jobs more effectively. When additional money is provided by the state or national government, offices would be able to hire more attorneys for each firm. This solution would help to both decrease the total caseload of public defenders and increase the amount of time a lawyer can spend on a case, because now there would be fewer cases to worry about. Additionally, public defender offices would be able to hire and obtain greater resources that would benefit each client and lawyer alike, such as sophisticated technology, private investigators, and forensic scientists. Second, public defender offices should create divisions within each office based upon certain infractions and categories within the justice system. When an office assigns their attorneys to a case based upon personal interest, the lawyer is more inclined to become passionate and invested in the case. Now, each lawyer will be able to work and engage within their own niche of the legal system. Essentially, the implementation of both solutions will boost public defender moral and work ethic, therefore making the guarantee of the sixth amendment utterly effective.

\section{Limitations}

Considering performing the necessary calculations for this research that have not been completed before, minor limitations developed over the course of the paper, both affecting the completion of the paper and the solutions instituted. First, regarding its completion, the original research question was to study the five most highly populated African American cities within the entire United States. After contacting multiple public defenders within each of the five cities, the state that provided the most specific and valuable information for this paper was Michigan, limiting the scope of this research. This, however, allowed the research to pinpoint specific problems within the justice system that could be applied to the rest of the nation. Corresponding to the increase in funding for public defender offices, there are only so many ways to materialize the necessary funds for efficient practice. Without raising taxes in each state, it may be difficult to determine what other programs the funds can be taken from. However, there are federal programs that can help subsidize the funds for these offices, like the Criminal Justice Act, helping to ensure a boost in work ethic and moral. Similarly, a limitation to the second solution of creating divisions within each office is that there may not be enough public defenders to work each branch. Regardless, an increase in funding would give way to an increase in staff at each office and allow the second solution to become successful.

\section{Further Research:}

To be able to apply these solutions to other parts of the United States, further research needs to be done within the legal system. By studying public defenders in multiple cities within the nation, one can correlate the results to pinpoint a more accurate and widespread problem and, in conjunction, a solution. Additionally, more factors should be examined to create a comprehensive means of measuring work ethic. Regarding choosing to study African American cities in response to Sharazi's study on high crime areas, more research should be completed on African Americans and their effect on and by the justice system, evaluating the differences between other racial and demographical neighborhoods. Through this research, other significant problems within the legal system such as recidivism and mass incarceration could be thoroughly examined and solved.

\section{Works Cited}

Bureau of Justice Statistics. (2014, April 22). 3 IN 4 FORMER PRISONERS IN 30 STATES ARRESTED WITHIN 5 YEARS OF RELEASE. Retrieved from https://www.bjs.gov/content/pub/press/rprts05p0510pr.cfm

Davis, J. (2018). Mastering the Art of Jury Selection. Jury Selection: The Art of Peremptoriness and Trial Advocacy Techniques. Retrieved from http://www.ncids.org/defender training/2018HighLevelFelony/JurySelection.pdf

Devers, L. (2011). Plea and Charge Bargaining Research Summary. Bureau of Justice Assistance - U.S. Department of Justice. Retrieved from https://www.bja.gov/Publications/PleaBargainingResearchSummary.pdf.

Fabelo, T. (n.d.). What Policymakers Need To Know To Improve Public Defense Systems. Harvard University's John F. Kennedy School of Government, 2nd ser.G. (2018). Florida. Retrieved from http://gideonat50.org/in-your-state/florida/

M. (n.d.). Caseload Reports. Retrieved from https://courts.michigan.gov/education/stats/Caseload/Pages/2017-CaseloadReports.aspx

Shirazi, R. (2016). It's High Time to Dump the High Crime Area Factor. Berkeley Journal of Criminal Law, 21(2). Retrieved from

https://scholarship.law.berkeley.edu/cgi/viewcontent.cgi?referer=https://www.google.com/\&httpsredir=1\&article=1108\&context =bjcl. 
U. (n.d.). Facts and Case Summary - Gideon v. Wainwright. Retrieved from https://www.uscourts.gov/educationalresources/educational-activities/facts-and-case-summary-gideon-v-wainwright

United States Department of Justice, Office of Justice Programs, \& Bureau of Justice Statistics. (2011, May 13). Census of Public Defender Offices: State Programs, 2007 (ICPSR 29501). Retrieved from Why Trial by Jury is Usually a Better Choice than a Bench Trial. (n.d.). Retrieved from https://www.hg.org/legal-articles/why-trial-by-jury-is-usually-a-betterchoice-than-a-bench-trial-6613

Worgul, M. (2014, August 26). Should I Waive the Preliminary Hearing? - Pittsburgh Criminal Lawyers. Retrieved from https://www.pittsburghcriminalattorney.com/should-you-waive-your-preliminary-hearing/

\section{Bibliography}

B. (2010, September 16). Office of Justice Programs. Retrieved fromhttps://ojp.gov/newsroom/pressreleases/2010/BJS10122.htm Beeman, M. (august 31, 2012). Using Data to Sustain and Improve Public Defense Systems. The American Bar Association. Retrieved from

https://www.americanbar.org/content/dam/aba/administrative/legal_aid_indigent_defendants/ls_sclaid_def_sustaining_and_impr oving_public_defense.authcheckdam.pdf.

Bender, L. A. (2011). Eliminating Excessive Public Defender Workloads. Retrieved from https://www.americanbar.org/content/dam/aba/publications/criminal_justice_magazine/cjsu11_benner.authcheckdam.p

df

Berezow, A. (2017, August 10). African-American Homicide Rate Nearly Quadruple the National Average. Retrieved from https://www.acsh.org/news/2017/08/10/african-american-homicide-rate-nearly-quadruple-national-average-11680

Braga, A. A., \& Brunson, R. K. (may 2015). The Police and Public Discourse on "Black-on-Black" Violence. New Perspectives in Policing. Retrieved from https://www.hks.harvard.edu/sites/default/files/centers/wiener/programs/pcj/files/PoliceandPublicDiscourseBlackonBla ckViolence.pdf.

Bureau of Justice Statistics. (2014, April 22). 3 IN 4 FORMER PRISONERS IN 30 STATES ARRESTED WITHIN 5 YEARS OF RELEASE. Retrieved from https://www.bjs.gov/content/pub/press/rprts05p0510pr.cfm

Davis, J. (2018). Mastering the Art of Jury Selection. Jury Selection: The Art of Peremptoriness and Trial Advocacy Techniques. Retrieved from http://www.ncids.org/defender training/2018HighLevelFelony/JurySelection.pdf

Devers, L. (2011). Plea and Charge Bargaining Research Summary. Bureau of Justice Assistance - U.S. Department of Justice. Retrieved from https://www.bja.gov/Publications/PleaBargainingResearchSummary.pdf.

Fabelo, T. (n.d.). What Policymakers Need To Know To Improve Public Defense Systems. Harvard University's John F. Kennedy School of Government, 2nd ser.G. (2018). Florida. Retrieved from http://gideonat50.org/in-your-state/florida/

Hanna, E. (November 6, 2018). Big Law, Public Defender-Style: Aggregating Resources to Ensure Uniform Quality of Representation. Washington and Lee Law Review Online, 74(2). Retrieved from https://scholarlycommons.law.wlu.edu/cgi/viewcontent.cgi?article=1100\&context=wlulr-online

Joy, P. A., \& McMunigal, K. C. (spring 2012). Does the Lawyer Make a Difference? Public Defender v. Appointed Counsel. Criminal Justice: The American Bar Association, 27(1).

LII Staff. (2017, October 10). Sixth Amendment. Retrieved from https://www.law.cornell.edu/constitution/sixth_amendment

M. (n.d.). Caseload Reports. Retrieved from https://courts.michigan.gov/education/stats/Caseload/Pages/2017-CaseloadReports.aspx

S. (2010, January). Criminal Justice Facts. Retrieved from https://www.sentencingproject.org/criminal-justice-facts/

Shirazi, R. (2016). It's High Time to Dump the High Crime Area Factor. Berkeley Journal of Criminal Law, 21(2). Retrieved from

https://scholarship.law.berkeley.edu/cgi/viewcontent.cgi?referer=https://www.google.com/\&httpsredir=1\&article=1108\&context $=$ bjcl.

U. (n.d.). Facts and Case Summary - Gideon v. Wainwright. Retrieved from https://www.uscourts.gov/educational-

resources/educational-activities/facts-and-case-summary-gideon-v-wainwright

United States Department of Justice, Office of Justice Programs, \& Bureau of Justice Statistics. (2011, May 13). Census of Public Defender Offices: State Programs, 2007 (ICPSR 29501). Retrieved from Why Trial by Jury is Usually a Better Choice

than a Bench Trial. (n.d.). Retrieved from https://www.hg.org/legal-articles/why-trial-by-jury-is-usually-a-better-choice-than-abench-trial-6613

Worgul, M. (2014, August 26). Should I Waive the Preliminary Hearing? - Pittsburgh Criminal Lawyers. Retrieved from https://www.pittsburghcriminalattorney.com/should-you-waive-your-preliminary-hearing/

2. (n.d.). Metro Areas With Largest African American Population. Retrieved from http://blackdemographics.com/population/black-city-population/ 